\title{
DELIMITAÇÃO DOS ÍNDICES DE FRAGILIDADE AMBIENTAL DO MUNICÍPIO DE SÃO LOURENÇO DO SUL/RS: SUBSÍDIO PARA O PLANEJAMENTO E GESTÃO AMBIENTAL
}

\author{
DELIMITATION OF ENVIRONMENTAL FRAGILITY INDEXES OF SÃO LOURENÇO DO
} SUL/RS: SUBSIDY FOR ENVIRONMENTAL PLANNING AND MANAGEMENT

\author{
Gisanara Dors ${ }^{1}$ \\ Diuliana Leandro ${ }^{2}$ \\ Samanta Tolentino Cecconello ${ }^{3}$ \\ Andréa Souza Castro ${ }^{4}$ \\ Willian Cézar Nadaleti ${ }^{5}$ \\ Suelen Cristina Movio Huinca ${ }^{6}$
}

\begin{abstract}
RESUMO
A conciliação entre o meio ambiente e o desenvolvimento das atividades antrópicas constitui um desafio para a gestão e planejamento dos recursos naturais, visto que o uso indevido do solo pode ocasionar danos significativos à sociedade. Os estudos de fragilidade ambiental buscam auxiliar neste planejamento e gestão visando garantir a sustentabilidade do ambiente. O objetivo deste trabalho foi mapear a fragilidade ambiental do município de São Lourenço do Sul, aplicando técnicas de Sistemas de Informação Geográfica, que possibilitam a avaliação das potencialidades do meio ambiente de forma integrada, compatibilizando suas características naturais com suas restrições. Para a confecção dos mapas temáticos de índice de fragilidade ambiental foi aplicado o modelo Índice de Fragilidade Ambiental que utilizou como critérios: a declividade do terreno, tipo de solo, litologia, clima, mata ciliar, ocupação humana, cobertura vegetal e o uso do solo. O modelo se mostrou eficaz e identificou que os índices de fragilidade Muito Alto, Alto e Médio, representaram 30,3\%,67,1\% e 2,6\%, respectivamente, da área total do município. $\mathrm{O}$ índice de fragilidade Muito Alto está associado às áreas de planícies fluviais. Por outro lado o índice de fragilidade Alto está relacionado principalmente à cobertura vegetal, o uso do solo e a extensa malha hidrográfica do município.
\end{abstract}

\footnotetext{
${ }^{1}$ Doutora em Engenharia Química pela Universidade Federal de Santa Catarina (UFSC, 2011). Graduada em Engenharia Sanitária e Ambiental pela Universidade Federal de Pelotas. E-mail: gisadors@yahoo.com.br ${ }^{2}$ Doutora em Ciências Geodésicas pela Universidade Federal do Paraná (UFPR, 2013). Professora do Centro de Engenharias da Universidade Federal de Pelotas. E-mail: diuliana.leandro@ gmail.com ORCID: 0000-0002$8092-5550$

${ }^{3}$ Mestre em Ciências Ambientais pela Universidade Federal de Pelotas (UFPEL, 2019). E-mail: satolentino@gmail.com ORCID: 0000-0001-5903-62413

${ }^{4}$ Doutora em Recursos Hídricos e Saneamento Ambiental (UFRGS, 2011). Professora do Centro de Engenharias da Universidade Federal de Pelotas E-mail: andreascastro@gmail.com ORCID: 0000-0003-1989-684X

${ }^{5}$ Doutor em Engenharia Ambiental (UFSC, 2017). Pós-doutorado em Eng. Ambiental pela UFSC 2019).

Professor do Centro de Engenharias da Universidade Federal de Pelotas. E-mail: williancezarnadaletti@gmail.com ORCID: 0000-0002-4727-4127

${ }^{6}$ Doutora em Ciências Geodésicas (UFPR, 2014). Professora do Departamento de Engenharia Rural da FAEM Universidade Federal de Pelotas. E-mail: suelen.huinca@gmail.com ORCID: 0000-0002-3326-3961
}

Revista Gestão e Sustentabilidade Ambiental., v. 10, n. 4, p. 74-95, dez. 2021. 
Palavras-Chave: Índice de fragilidade ambiental. Planejamento ambiental. Mata ciliar.

\begin{abstract}
The conciliation between the environment and the development of human activities constitutes a challenge for the management and planning of natural resources, since the improper use of the soil can cause significant damage to society. Environmental fragility studies seek to assist in this planning and management in order to ensure the sustainability of the environment. The objective of this work was to map the environmental fragility of São Lourenço do Sul/RS, applying techniques of Geographic Information Systems, which enable the evaluation of environmental potentialities an integrated way, aligning its natural characteristics with its restrictions. In preparation of environmental fragility index themed maps was applied model Environmental Fragility Index that used as criteria: the terrain slope, soil type, lithology, climate, riparian forest, human occupation, vegetation cover and the use of soil. The model was effective and identified that the Very High, High and Medium fragility indexes represent $30.3 \%$, $67.1 \%$ and $2.6 \%$, respectively, of the total area of the municipality. The Very High Fragility index is associated with the fluvial plains areas. On the other hand, the Alto fragility index is mainly related to the vegetation cover, land use and the extensive hydrographic network of the municipality.
\end{abstract}

Keywords: Environmental fragility index. Environmental planning. Riparian forest.

\title{
1 Introdução
}

Com a apropriação dos recursos naturais pelo homem, com o objetivo de garantir a subsistência e progresso da sociedade, diversos impactos ambientais surgiram. Esses impactos se deram em virtude da exploração intensa do meio natural que ultrapassaram a capacidade de resiliência do mesmo (CAMPOS et al., 2021). Deste modo, a natureza que estava em equilíbrio dinâmico, passou a ser modificada e degradada, provocando desequilíbrios que afetam drasticamente a vida da sociedade, dando origem ao que comumente se chama de desastres naturais (CECCONELLO, 2019). De acordo com Tominaga et al. (2009), diversos estudos indicam que a variabilidade climática, com tendência para o aquecimento global, está associada a um aumento de extremos climáticos. Nesta situação, os eventos de temporais, chuvas intensas, tornados ou estiagens severas, podem tornar-se mais frequentes, aumentando a possibilidade de ocorrência de desastres naturais.

Devido aos impactos negativos que as atividades antrópicas causam no ambiente natural, torna-se importante que sejam analisados de forma integrada os diferentes elementos 
naturais e as múltiplas atividades antrópicas, visando minimizar os impactos negativos que favorecem os desastres naturais (NGUYEN e LIOU, 2019). Segundo Anjinho et al. (2021) essa análise integrada dos múltiplos elementos ambientais, possibilitam o planejamento das intervenções antrópicas com o objetivo de reduzir os impactos sob os recursos naturais. Neste contexto, tem-se o estudo das fragilidades ambientais, que permite relacionar os diferentes componentes do ambiente com as ações antrópicas.

A fragilidade ambiental é também chamada de vulnerabilidade ambiental em diferentes abordagens ambientais (APS et al., 2018; SAHOO; DHAR; KAR, 2016; ZHAO et al., 2018). Ambas as terminologias representam a suscetibilidade do ambiente natural a mudanças em seu equilíbrio, provocando uma degradação ambiental de uma determinada unidade paisagística. Porém, em situações em que o solo tem um papel mais importante no processo, a análise da fragilidade ambiental tem se destacado como definição mais adequada para as abordagens ambientais (ARRIAGADA et al., 2019). Assim, estudos relativos à fragilidade dos ambientes são de extrema relevância ao planejamento ambiental visto que a identificação dos ambientes naturais e suas fragilidades proporcionam uma melhor definição das diretrizes e ações a serem implementadas no espaço físico - territorial, servindo de base para o zoneamento e fornecendo subsídios à gestão do território (SPÖRL e ROSS, 2004).

Para Spörl e Ross (2004) o termo fragilidade ambiental está ligado à susceptibilidade do sistema de sofrer intervenções ou de ser alterado. Quando é quebrado o estado de equilíbrio dinâmico o sistema pode entrar em colapso, passando para uma situação de risco. A desestabilização do sistema pode ter como indutores tanto processos naturais, quanto ações antrópicas. Segundo Ross (1994), os sistemas ambientais, face às intervenções antrópicas, apresentam maior ou menor fragilidade e qualquer alteração nos diferentes componentes da natureza (relevo, solo, vegetação, clima e recursos hídricos) acarreta o comprometimento da funcionalidade do sistema, quebrando o seu estado de equilíbrio dinâmico. De acordo com Nguyen e Liou (2019) é necessário desenvolver uma maneira confiável de caracterizar de forma abrangente a resposta do meio ambiente tanto na direção natural quanto na direção das forças humanas. Forças motrizes, como fatores naturais e atividades humanas, que incluem a agricultura, indústria, urbanização e mudança climática, aumentam a pressão sobre os recursos naturais, um exemplo disso é a profunda transformação da urbanização das paisagens naturais em todo o mundo (AKBARI, NEAMATOLLAHI; NEAMATOLLAHI, 2019).

Revista Gestão e Sustentabilidade Ambiental., v. 10, n. 4, p. 74-95, dez. 2021. 


\section{GESTÃO \& SUSTENTABILIDADE} AMBIENTAL

\section{৩unisul}

Os modelos de simulação ambiental fornecem diagnósticos e saídas preditivas, que podem ser combinadas com dados socioeconômicos para avaliação de riscos ambientais regionais e locais, ou decisões relacionadas com o gerenciamento de recursos naturais (STEYAERT, 1993). No entanto, é preciso observar conforme Felgueiras (2001), que os processos da natureza resultam de interações espaço-temporais complexas, essa complexidade pode incluir comportamentos não lineares, componentes estocásticos e realimentações em múltiplas escalas de tempo e de espaço.

No Brasil, o estudo da fragilidade ambiental, foi proposto por Ross (1994), sendo desenvolvido com base nos conceitos de Ecodinâmica e Ecossistema definidos por Tricart (1977). A metodologia de Ross (1994) pressupõe que a natureza apresenta funcionalidade intrínseca entre seus elementos físicos e bióticos, como geologia, clima, tipos de solos e cobertura vegetal. Sendo assim, as fragilidades ambientais de determinada área, visam mostrar o quanto está área é suscetível à degradação ambiental por meio de processos intensificados pelas ações humanas (ANJINHO et al., 2021; OLIVEIRA-ANDREOLI et al., 2021).

Os estudos relativos à fragilidade dos ambientes são de extrema relevância ao planejamento ambiental visto que a identificação dos ambientes naturais e suas fragilidades proporcionam uma melhor definição das diretrizes e ações a serem implementadas no espaço físico - territorial, servindo de base para o Zoneamento Ecológico Econômico (ZEE) e fornecendo subsídios à gestão do território, tornando-se, portanto, uma ferramenta importante para a estruturação do planejamento e gestão ambiental sustentável por meio do mapeamento das fragilidades ambientais (ANJINHO et al., 2021; CRUZ et al., 2017; SAHOO et al., 2019).

De acordo com Trevisan et al. (2020), o estudo de fragilidade ambiental permite verificar os possíveis problemas ambientais e levar à implementação de convenções internacionais, programas de ação e políticas locais, regionais e nacionais, pois utiliza ferramentas sofisticadas como os Sistemas de Informação Geográfica (SIG) para mapear as áreas de fragilidade ambiental. Desta forma, os mapeamentos de fragilidade ambiental possibilitam a indicação de áreas nas quais os graus de fragilidade são mais baixos, com maiores opções de uso e ocupação; e aquelas de graus de fragilidade mais altos, áreas mais vulneráveis, nas quais as opções de uso são mais reduzidas (ARRIAGADA et al., 2019; CAMPOS et al., 2021; SANTOS et al., 2010; SPÖRL e ROSS, 2004). 
No Brasil, muitos estudos têm sido realizados, utilizando adaptações dos modelos consagrados de Ross (1994) e Crepani et al. (2001), como por exemplo, os estudos de Corte et al. (2015), Cruz et al. (2017), Macedo et al. (2018), Manfré et al. (2013). Em 2013, Leandro propôs uma nova metodologia para a determinação do índice de fragilidade ambiental inserindo ao modelo proposto por Ross (1994) e Crepani et al. (2001) duas novas variáveis: existência de Áreas de Preservação Permanente e a Ocupação Humana. Para ponderar os elementos ambientais do modelo proposto, a autora realizou uma série de testes com variações nos pesos e posterior visualização dos resultados obtidos nos mapas de fragilidade ambiental, considerando a capacidade do modelo em identificar as áreas conhecidas de fragilidade ambiental para a Bacia do Rio Iraí.

A região Sul do Brasil, especialmente o Rio Grande do Sul (RS), é uma região bastante impactada por eventos meteorológicos extremos, como tempestades, chuvas intensas e secas. Tendo ciência de que o município de São Lourenço do Sul/RS, objeto do estudo, vem sofrendo intensas modificações por interferências antrópicas, decorrentes de ações que visam o desenvolvimento econômico do município, e que ocasionam alterações nas suas condições naturais, torna-se essencial o planejamento territorial e ambiental do município. Ademais, São Lourenço do Sul no ano de 2011 sofreu com intensas chuvas que fizeram com que o nível de água do arroio São Lourenço subisse cerca de três metros de altura, deixando $50 \%$ da área urbana alagada, estradas e pontes das áreas rurais também acabaram sendo destruídas, causando dificuldades para o acesso da população rural à cidade, provocando uma série de prejuízos econômicos e sociais para o município (SAUSEN et al., 2012). Dentre os principais problemas relacionados a este desastre no município está a falta de práticas adequadas de manejo do solo e da água e a inexistência de planejamento ambiental (BARBOSA JÚNIOR, 2017). Além de inexistirem estudos de fragilidade ambiental para o município de São Lourenço do Sul que contemple diferentes elementos antrópicos e não apenas os elementos naturais, como o considerado, por exemplo, no Zoneamento Ecológico Econômico (ZEE). O ZEE está sendo elaborado para o Rio Grande do Sul pela Secretaria de Meio Ambiente do Estado (SEMA/RS) e leva em consideração apenas as características intrínsecas do município para assim determinar suas vulnerabilidades, deste modo, este trabalho busca fornecer subsídios para uma análise integrada do ambiente através do cruzamento de diferentes planos de informação sobre o ambiente antrópico e natural do município.

Revista Gestão e Sustentabilidade Ambiental., v. 10, n. 4, p. 74-95, dez. 2021. 


\section{¿unisul}

Dentro deste contexto, o objetivo deste trabalho foi estudar a fragilidade ambiental do município de São Lourenço do Sul/RS, aplicando a metodologia proposta por Leandro (2013), tendo como produto final o mapeamento da fragilidade ambiental que permite a avaliação das potencialidades do meio ambiente de forma integrada, compatibilizando suas características naturais com suas restrições.

\section{Metodologia}

\subsection{Caracterização da área de estudo}

O município de São Lourenço do Sul está localizado no Sudeste do Estado do RS, na margem direita da Lagoa dos Patos, tendo como limites os municípios de Camaquã, Cristal, Canguçu, Turuçu e Pelotas (Figura 1) e é cortado pela BR-116. A área total do município é de $2036,12 \mathrm{~km}^{2}$, tem uma população de 43.111 habitantes, sendo $56,22 \%$ residente na zona urbana e 43,78\% na zona rural (IBGE, 2010).

Figura 1. Localização da área de estudo - Município de São Lourenço do Sul - RS.

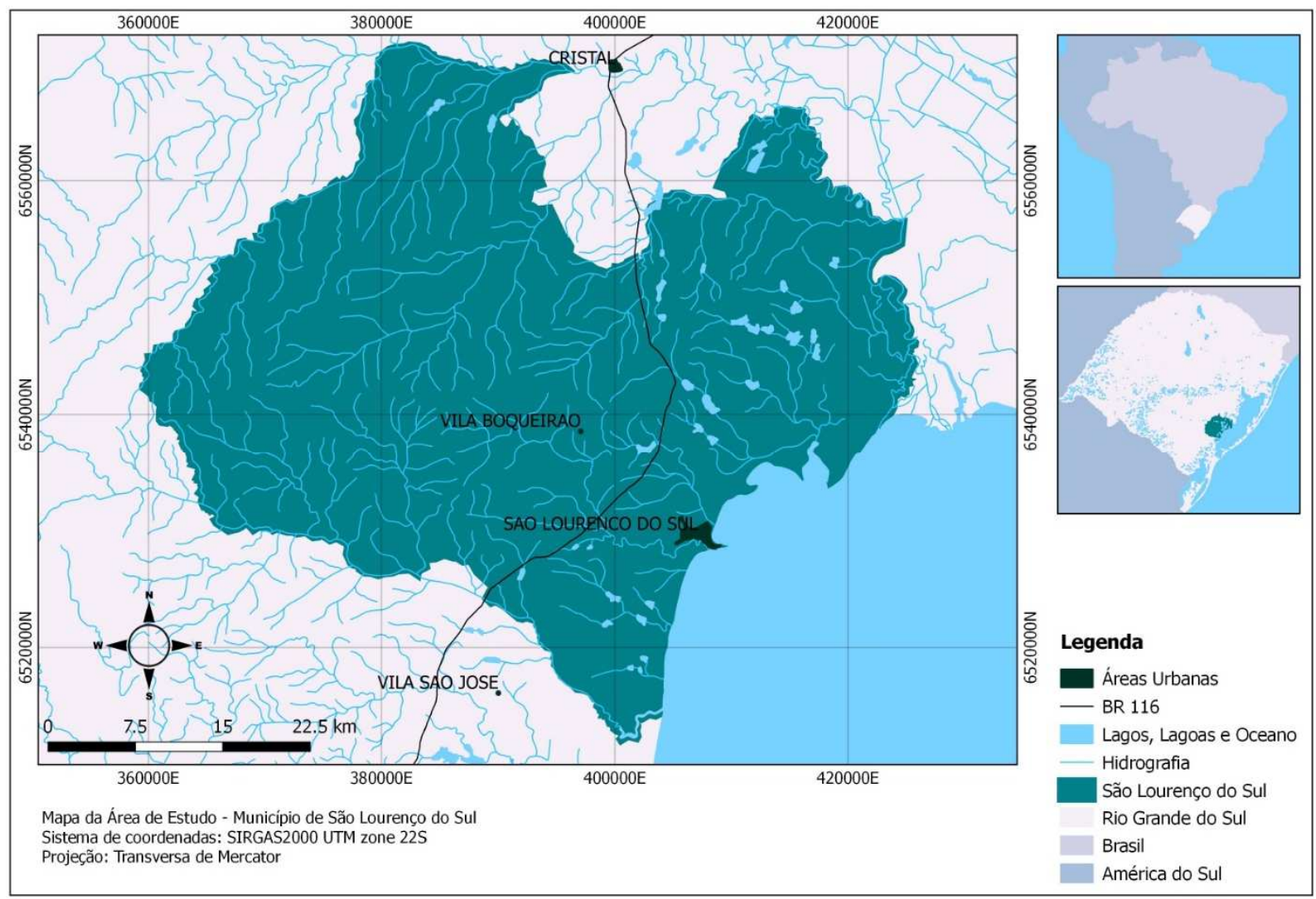

Fonte: Elaborado pelos autores.

Revista Gestão e Sustentabilidade Ambiental., v. 10, n. 4, p. 74-95, dez. 2021. 
Conforme dados do IBGE (2021), o município no setor primário destaca-se pela diversidade nas atividades agrícolas de base familiar: silvicultura (extrativismo de madeira para fins energéticos), fruticultura, monoculturas de arroz e soja, fumicultura, pastagem (para pecuária de corte e leiteira) e lavouras de milho, feijão e hortaliças. Além de ser um importante polo turístico para a região sul do Estado.

São Lourenço do Sul está situado entre duas unidades geomorfológicas, representadas pelo Escudo Sul-Riograndense que é constituído por rochas cristalinas; e pela Planície Costeira constituída basicamente por sedimentos continentais provindos das regiões mais altas e sedimentos marinhos originados das regressões e transgressões marinhas (TOMAZELLI et al., 2007). As cotas variam entre 0 a $450 \mathrm{~m}$, aproximadamente. O município se caracteriza pela presença de uma topografia ondulada a oeste da BR-116 a qual permite o escoamento superficial das águas, enquanto a leste, situa-se o relevo de planície, que favorece a acumulação das águas (CUNHA, SILVEIRA, SEVERO, 2006).

São Lourenço do Sul pertence à bacia hidrográfica do Litoral e à sub-bacia hidrográfica Camaquã. A nordeste o rio Camaquã faz a divisão municipal entre São Lourenço do Sul e Camaquã, estendendo-se por $75 \mathrm{~km}$ de território do município. As bacias que atravessam a área urbana são as bacias do arroio São Lourenço (ao sul da cidade) e do arroio Carahá (ao norte). Estes arroios deságuam na Laguna dos Patos, cuja extensão no município forma um litoral de aproximadamente $69 \mathrm{~km}$ (CEPED/RS, 2015). Os tipos de cobertura vegetal e uso do solo no município estão diretamente relacionados aos padrões de relevo existentes. No setor de Planalto, há uma forte presença da agricultura familiar e da policultura da batata, feijão, milho e fumo, além da atividade leiteira. No setor de Planície, em função da aptidão do solo, persiste a rizicultura, plantio de soja e também a pecuária extensiva (LIMA, 2006).

\subsection{Fonte e tratamento dos dados}

Neste trabalho foram utilizados diferentes documentos cartográficos de diversas fontes, conforme a Tabela 1.

Tabela 1. Dados cartográficos.

\begin{tabular}{lccc}
\hline Dados & Escala & Fonte/ Data & Sistema de Referência \\
\hline Cobertura Vegetal & $1: 250.000$ & FEPAM/2005 & SIRGAS2000 \\
\hline Tipo de solo & $1: 250.000$ & FEPAM/2005 & SIRGAS2000 \\
\hline Uso do solo & $1: 100.000$ & IBGE/ 2010 & SIRGAS2000 \\
\hline
\end{tabular}

Revista Gestão e Sustentabilidade Ambiental., v. 10, n. 4, p. 74-95, dez. 2021. 


\section{¿unisul}

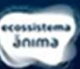

\begin{tabular}{lccc}
\hline Climatológicos & $1: 500.000$ & IBGE/ 2002 & WGS-84 \\
\hline Geológicos & $1: 1.000 .000$ & IBGE/ 2004 & SAD69 \\
\hline Hidrográficos & $1: 100.000$ & IBGE/ 2010 & SIRGAS2000 \\
\hline Altimétricos & $1: 250.000$ & FEPAM/2005 & SIRGAS2000
\end{tabular}

Fonte: Autores.

A partir destes dados espaciais foram gerados os documentos cartográficos da declividade do terreno, tipo de solo, litologia, clima, hidrografia, cobertura vegetal e o uso do solo. Estes documentos cartográficos foram utilizados na modelagem do IFA, que gerou os mapas temáticos de índice fragilidade ambiental do município de São Lourenço do Sul.

Todos os dados, independentemente do sistema de referência inicial, foram alocados no banco de dados em um sistema de referência único, Datum horizontal Sistema de Referência Geocêntrico para as Américas - 2000 (SIRGAS2000), projetados em UTM (Universal Transversa de Mercator) no fuso 22 sul. O software utilizado para o tratamento dos dados e modelagem foi o Quantum GIS versão 2.14.0-Essen.

\subsection{Modelo do Índice de Fragilidade Ambiental (IFA)}

De acordo com Leandro (2013) a construção do modelo para a determinação do índice de fragilidade ambiental, considera os aspectos envolvidos e a relevância significativa de cada critério utilizado no desenvolvimento do modelo matemático. Este trabalho utilizou como base o estudo desenvolvido por Leandro (2013), portanto adotaram-se os seguintes critérios para o desenvolvimento do modelo matemático: a declividade do terreno, solo, litologia, clima, ocupação humana, mata ciliar, cobertura vegetal e uso do solo. A modelagem IFA utiliza critérios comuns as metodologias de Ross (1994), de Crepani et al. (2001) e de Spörl (2007).

No modelo IFA, cada critério foi classificado em cinco classes: Muito Baixo, Baixo, Médio, Alto e Muito Alto; exceto o critério mata ciliar que foi classificado em três classes: Baixo, Médio e Alto. A cada uma dessas classes associou-se um valor numérico entre 1 e 5. Os critérios receberam uma ponderação com valores variando de 7 a 1 (Tabela 2). A opção por esses pesos se deu após uma série de testes com variações nos pesos e visualização dos mapas temáticos de fragilidade gerados, considerando capacidade do modelo em demarcar ou não de áreas conhecidas de risco ambiental no estudo realizado por Leandro (2013).

Tabela 2. Ponderação dos critérios das variáveis utilizadas na modelagem IFA.

Revista Gestão e Sustentabilidade Ambiental., v. 10, n. 4, p. 74-95, dez. 2021. 


\section{GESTÃO \& SUSTENTABILIDADE} AMBIENTAL

\section{ounisul}

\begin{tabular}{lll}
\hline & Critério & Peso \\
\hline 1 & Declividade do Terreno & 7 \\
\hline 2 & Cobertura Vegetal e Uso do Solo & 6 \\
\hline 3 & Mata ciliar & 6 \\
\hline 4 & Ocupação Humana & 5 \\
\hline 5 & Tipo de Solo & 1 \\
\hline 6 & Litologia & 1 \\
\hline 7 & Clima & 1 \\
\hline
\end{tabular}

Fonte: Leandro (2013).

A equação do modelo linear IFA, proposto por Leandro (2013) e adotada neste estudo foi:

$$
G F_{I F A}=7 * C_{1}+C_{2}+6 * C_{3}+C_{4}+C_{5}+5 * C_{6}+6 * C_{7}
$$

Onde: $\mathrm{GF}_{\mathrm{IFA}}=$ grau de fragilidade $\mathrm{C}_{1}=$ grau de fragilidade relativo à declividade do terreno; $\mathrm{C}_{2}=$ grau de fragilidade relativo ao tipo de solo; $\mathrm{C}_{3}=$ grau de fragilidade relativo à cobertura vegetal e uso do solo; $\mathrm{C}_{4}=$ grau de fragilidade relativo ao clima; $\mathrm{C}_{5}=$ grau de fragilidade relativo à litologia; $\mathrm{C}_{6}=$ grau de fragilidade relativo à ocupação humana; $\mathrm{C}_{7}=$ grau de fragilidade relativo à existência de mata ciliar.

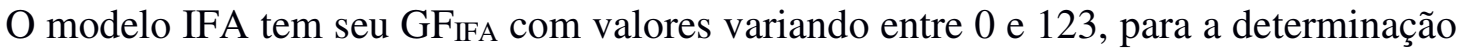
desse intervalo submeteu-se a delimitação dos valores para as situações mais extremas, e simulou-se os índices de fragilidade dentro de cada critério. Esse intervalo foi subdividido em 5 classes: Muito Baixo, Baixo, Médio, Alto e Muito Alto, conforme a Tabela 3.

Tabela 3. Intervalo de classes do modelo IFA.

\begin{tabular}{ccc}
\hline Classes & Índice de Fragilidade Ambiental & Intervalo da Classe \\
\hline 1 & Muito Baixo & $0-34$ \\
\hline 2 & Baixo & $34-41$ \\
\hline 3 & Médio & $41-48$ \\
\hline 4 & Alto & $48-55$ \\
\hline 5 & Muito Alto & $55-123$ \\
\hline
\end{tabular}

Fonte: Leandro (2013).

\subsection{Critérios do modelo IFA}

Revista Gestão e Sustentabilidade Ambiental., v. 10, n. 4, p. 74-95, dez. 2021. 


\section{GESTÃO \& SUSTENTABILIDADE AMBIENTAL

O critério de declividade do terreno considerou a metodologia proposta por Ross (1994), na qual os índices de fragilidade estão relacionados a intervalos de declividade do terreno e consequentemente as formas de relevo, como apresentado na Tabela 4.

Tabela 4. Classes para o critério declividade do terreno.

\begin{tabular}{lccc}
\hline $\begin{array}{c}\text { Intervalos de } \\
\text { declividade }\end{array}$ & Forma de Relevo & Valor & $\begin{array}{c}\text { Índice de Fragilidade } \\
\text { Ambiental }\end{array}$ \\
\hline Até $6 \%$ & Plano & 1 & Muito Baixo \\
\hline 6 a $12 \%$ & Suavemente ondulado & 2 & Baixo \\
\hline 12 a $20 \%$ & Ondulado & 3 & Médio \\
\hline 20 a $30 \%$ & Abrupto & 4 & Alto \\
\hline Acima de $30 \%$ & Muito abrupto & 5 & Muito Alto
\end{tabular}

Fonte: Adaptado de Ross (1994), Leandro (2013).

Ross (1994) também criou uma hierarquização da fragilidade ambiental de vários tipos de solo levando em consideração a textura, o grau de coesão das partículas, estrutura e plasticidade dos solos (Tabela 5).

Tabela 5. Classes para o critério solo.

\begin{tabular}{lcc}
\hline \multicolumn{1}{c}{ Tipos de Solo } & Valor & $\begin{array}{c}\text { Índice de Fragilidade } \\
\text { Ambiental }\end{array}$ \\
\hline $\begin{array}{l}\text { Latossolo Bruno, Latossolo Roxo, Latossolo Vermelho } \\
\text { escuro e Vermelho amarelo textura argilosa }\end{array}$ & 1 & Muito Baixo \\
\hline $\begin{array}{l}\text { Latossolo Amarelo e Vermelho amarelo textura média / } \\
\text { argilosa }\end{array}$ & 2 & Baixo \\
\hline Latossolo Vermelho amarelo, Argilosos & 3 & Médio \\
\hline Argissolos textura média / arenosa, Cambissolos & 4 & Alto \\
\hline Neossolos, Organossolos & 5 & Muito Alto \\
\hline
\end{tabular}

Fonte: Adaptado de Ross (1994).

Com relação à litologia, ou seja, quanto ao tipo de rocha de que é constituída e suas características físicas (composição mineral, distribuição e tamanho dos grãos, cor, textura, estrutura e grau de compactação dos sedimentos ou rochas); utilizou-se a escala de índice de 
fragilidade desenvolvida por Crepani et al. (2001), relacionando-as a sua resistência ao intemperismo, como pode ser observado na Tabela 6.

Tabela 6. Classes para o critério litologia.

\begin{tabular}{|c|c|c|c|}
\hline $\begin{array}{l}\text { Tipos de } \\
\text { Rochas }\end{array}$ & Litologias & Valor & $\begin{array}{c}\text { Índice de Fragilidade } \\
\text { Ambiental }\end{array}$ \\
\hline Metamórficas & Quartizitos ou metaquartizitos & \multirow{4}{*}{1} & \multirow{4}{*}{ Muito Baixo } \\
\hline Ígneas & Riolito, Granito, Dacito & & \\
\hline $\begin{array}{l}\text { Ígneas } \\
\text { Intrusivas }\end{array}$ & Granodiorito, Granulitos & & \\
\hline Metamórficas & Migmatitos, Gnaisses & & \\
\hline $\begin{array}{l}\text { Ígneas } \\
\text { Intrusivas }\end{array}$ & $\begin{array}{l}\text { Fonólito, Nefelina Sienito, } \\
\text { Traquito, Sienito }\end{array}$ & \multirow{4}{*}{2} & \multirow{4}{*}{ Baixo } \\
\hline Ígneas & Andesito, Diorito, Basalto & & \\
\hline $\begin{array}{l}\text { Ígneas } \\
\text { Intrusivas }\end{array}$ & Anortosito, Gabro, Peridotito & & \\
\hline Metamórficas & $\begin{array}{l}\text { Milonitos, Quartzo muscovita, } \\
\text { Biotita-xisto, Clorita xisto }\end{array}$ & & \\
\hline $\begin{array}{l}\text { Ígneas e } \\
\text { Metamórficas }\end{array}$ & $\begin{array}{l}\text { Piroxenito, Anfibolito Kimberlito, } \\
\text { Dunito }\end{array}$ & \multirow{5}{*}{3} & \multirow{5}{*}{ Médio } \\
\hline Ígneas & $\begin{array}{l}\text { Homblenda, Tremolita, Actinolita } \\
\text { xisto }\end{array}$ & & \\
\hline Metamórficas & Estaurolita xisto, xistos granatíferos & & \\
\hline Metamórficas & Filito, Metassiltito & & \\
\hline Metamórficas & Ardósia, Metargilito & & \\
\hline Metamórficas & Mármores & \multirow{4}{*}{4} & \multirow{4}{*}{ Alto } \\
\hline Sedimentares & $\begin{array}{l}\text { Arenitos quartzosos ou } \\
\text { Ortoquartizitos }\end{array}$ & & \\
\hline Sedimentares & Conglomerados, Subgrauvacas & & \\
\hline Sedimentares & Grauvacas, Arcózios & & \\
\hline Sedimentares & Siltitos, Argilitos & 5 & Muito Alto \\
\hline
\end{tabular}




\section{GESTÃO \& SUSTENTABILIDADE} AMBIENTAL

\section{¿unisul}

\begin{tabular}{ll}
\hline Sedimentares & Folhelhos \\
\hline Sedimentares & $\begin{array}{l}\text { Calcários, Dolomitos, Margas, } \\
\text { Evaporitos }\end{array}$ \\
\hline Sedimentares & $\begin{array}{l}\text { Sedimentos Inconsolidados: } \\
\text { Aluviões, Colúvios. }\end{array}$
\end{tabular}

Fonte: Adaptado de Crepani et al. (2001).

Ao critério clima estão relacionados fatores de precipitação pluviométrica e de temperatura, utilizou-se a metodologia proposta por Spörl (2007) e na Tabela 7 são apresentadas as características pluviométricas associadas ao índice de fragilidade ambiental.

Tabela 7. Classes para o critério clima.

\begin{tabular}{|c|c|c|}
\hline Características pluviométricas & Valor & $\begin{array}{c}\text { Índice de Fragilidade } \\
\text { Ambiental }\end{array}$ \\
\hline $\begin{array}{l}\text { Situação pluviométrica com distribuição regular ao longo } \\
\text { do ano, com volumes não muito superiores a } \\
1000 \mathrm{~mm} / \text { ano }\end{array}$ & 1 & Muito Baixo \\
\hline $\begin{array}{l}\text { Situação pluviométrica com distribuição regular ao longo } \\
\text { do ano, com volumes anuais não muito superiores a } \\
2000 \mathrm{~mm} / \text { ano }\end{array}$ & 2 & Baixo \\
\hline $\begin{array}{l}\text { Situação pluviométrica com distribuição anual desigual, } \\
\text { com períodos secos entre } 2 \text { e } 3 \text { meses de inverno, e no } \\
\text { verão com maiores intensidades de dezembro a março }\end{array}$ & 3 & Médio \\
\hline $\begin{array}{l}\text { Situação pluviométrica com distribuição anual desigual, } \\
\text { com períodos secos entre } 3 \text { e } 6 \text { meses, e alta } \\
\text { concentração das chuvas no verão entre novembro e abril } \\
\text { quando ocorrem de } 70 \text { a } 80 \% \text { do total de chuvas }\end{array}$ & 4 & Alto \\
\hline $\begin{array}{l}\text { Situação pluviométrica com distribuição regular, ou não, } \\
\text { ao longo do ano, com grandes volumes anuais } \\
\text { ultrapassando } 2500 \mathrm{~mm} / \mathrm{ano} \text {; ou ainda, comportamentos } \\
\text { pluviométricos irregulares ao longo do ano, com } \\
\text { episódios de chuvas de alta intensidade e volumes anuais } \\
\text { baixos, geralmente abaixo de } 900 \mathrm{~mm} / \text { ano (semi-árido) }\end{array}$ & 5 & Muito Alto \\
\hline
\end{tabular}

Fonte: Spörl (2007).

Revista Gestão e Sustentabilidade Ambiental., v. 10, n. 4, p. 74-95, dez. 2021. 


\section{GESTÃO \& SUSTENTABILIDADE} AMBIENTAL

\section{Unisul}

As informações sobre o tipo de cobertura vegetal são fundamentais para subsidiar o planejamento ambiental e podem ser utilizadas como suporte qualitativo à análise de fragilidade ambiental. Os graus de proteção aos solos pela cobertura natural e cultivada, organizados por Ross (1994), obedecem às ordens decrescentes da capacidade de proteção, conforme mostra a Tabela 8.

Tabela 8. Classes para o critério cobertura vegetal e uso do solo.

\begin{tabular}{|c|c|c|}
\hline Tipos de cobertura vegetal & $\begin{array}{l}\text { Graus de } \\
\text { Proteção }\end{array}$ & $\begin{array}{c}\text { Índice de Fragilidade } \\
\text { Ambiental }\end{array}$ \\
\hline $\begin{array}{l}\text { Floresta/ Matas naturais, Florestas com } \\
\text { biodiversidade }\end{array}$ & 1 - Muito Alta & Muito Baixo \\
\hline $\begin{array}{l}\text { Formações arbustivas naturais com estrato } \\
\text { herbáceo denso. Formações arbustivas densas } \\
\text { (mata secundária, cerrado denso, capoeira densa). } \\
\text { Mata homogênea de Pinus densa. Pastagem } \\
\text { cultivada sem pisoteio de gado. Cultivo de ciclo } \\
\text { longo como o cacau }\end{array}$ & $2-$ Alta & Baixo \\
\hline $\begin{array}{l}\text { Cultivo de ciclo longo em curvas de nível/ } \\
\text { terraceamento como café, laranja com forrageiras } \\
\text { entre ruas. Pastagem com baixo pisoteio. } \\
\text { Silvicultura de eucaliptos com sub-bosques de } \\
\text { nativas }\end{array}$ & 3 - Média & Médio \\
\hline $\begin{array}{l}\text { Culturas de ciclo longo de baixa densidade (café, } \\
\text { laranja) com solo exposto entre as ruas, culturas de } \\
\text { ciclo curto (arroz, feijão, trigo, soja, milho, } \\
\text { algodão) com cultivo em curvas de } \\
\text { nível/terraceamento }\end{array}$ & 4 - Baixa & Alto \\
\hline
\end{tabular}

Áreas desmatadas e queimadas recentemente, solo

exposto por arado/gradeação, solo exposto ao longo de caminhos e estradas, terraplanagens, culturas de ciclo curto sem práticas

$$
5 \text { - Muito }
$$

conservacionistas, áreas alagadas e corpos de água

Baixa a Nula

Muito Alto superficiais

Fonte: Ross (1994).

Para o critério de ocupação humana utilizou-se na modelagem as características da Tabela 9, para qualificar as áreas de acordo com o índice de fragilidade ambiental em função do tipo de ocupação antrópica e a presença ou ausência de esgotamento sanitário. 
Tabela 9. Classes para o critério ocupação humana.

\begin{tabular}{lcc}
\hline \multicolumn{1}{c}{ Ação Antrópica } & Valor & $\begin{array}{c}\text { Índice de Fragilidade } \\
\text { Ambiental }\end{array}$ \\
\hline Estradas, sem ocupação & 1 & Muito Baixo \\
\hline $\begin{array}{l}\text { Edificações sem aglomerado humano, loteamento, } \\
\text { armazém, silo }\end{array}$ & 2 & Baixo \\
\hline $\begin{array}{l}\text { Indústrias, aglomerados humano (área urbana baixa e } \\
\text { média) com esgotamento sanitário }\end{array}$ & 3 & Médio \\
\hline $\begin{array}{l}\text { Indústrias e aglomerados humanos (área urbana alta) com } \\
\text { esgotamento sanitário, aglomerados humano (área urbana } \\
\text { baixa, média e alta) com esgotamento sanitário parcial } \\
\text { (vila), áreas de mineração, areais e granja }\end{array}$ & 4 & Alto \\
\hline $\begin{array}{l}\text { Indústrias e aglomerados urbanos sem esgotamento } \\
\text { sanitário }\end{array}$ & 5 & Muito Alto \\
\hline Fonte: Adaptado de Leandro (2013). & &
\end{tabular}

Fonte: Adaptado de Leandro (2013).

O critério mata ciliar foi subdividido em 3 classes: Alto, Médio e Baixo. O índice de fragilidade ambiental classifica as áreas pela existência ou não de mata ciliar no entorno dos corpos d'água (Tabela 10).

Tabela 10. Classes para o critério mata ciliar.

\begin{tabular}{lcc}
\hline \multicolumn{1}{c}{ Existência de mata ciliar } & Valor & $\begin{array}{c}\text { Índice de Fragilidade } \\
\text { Ambiental }\end{array}$ \\
\hline $\begin{array}{l}\text { Mata ciliar em corpos de água, naturais ou artificiais, 30 } \\
\text { metros em seu entorno }\end{array}$ & 1 & Alto \\
\hline $\begin{array}{l}\text { Áreas que distam até 500 metros da mata ciliar e de } \\
\text { corpos de água, sejam naturais ou artificiais }\end{array}$ & 2 & Médio \\
\hline Outras & 3 & Baixo \\
\hline Fonte: Adaptado de Leandro (2013) & &
\end{tabular}

Fonte: Adaptado de Leandro (2013).

\section{Resultados e discussão}

Cada um dos critérios analisados pelo modelo IFA foi hierarquizado em graus de fragilidade, que variaram entre Muito Baixo, Baixo, Médio, Alto e Muito Alto. 


\section{GESTÃO \& SUSTENTABILIDADE} AMBIENTAL

\section{¿unisul}

O critério clima apresentou um índice de fragilidade Baixo, considerando o tipo de clima subtropical pouco úmido com inverno frio e verão fresco e a pluviosidade do município, que de acordo com a Estação Boqueirão, mantida pela Agência Nacional de Águas (ANA), com período de observação de 47 anos (1966 - 2012), apresenta valores superiores a 1000 mm/ano e em alguns casos ultrapassa os $2000 \mathrm{~mm} / \mathrm{ano}$.

Steinmetz et al. (2015) concluíram em seu estudo que a bacia do Arroio São Lourenço não possui tendência à enchente e alagamentos em condições normais de precipitação. Entretanto, a análise de ordem dos canais indicou a possibilidade de aumento da vazão próximo ao exutório da bacia, em condições extremas de precipitação. Os autores destacam que o alto valor de precipitação média na bacia é bem distribuído ao longo do ano, e sugerem que medidas mitigadoras devem ser tomadas para minimizar os casos de enchentes na parte urbana da cidade, como por exemplo, o episódio que ocorreu em 2011 no município.

O município de São Lourenço do Sul apresentou índice de fragilidade Muito Baixo, em 66,6\% da área do município, na região do Escudo Cristalino Sul-Riograndense, que é composto por rochas ígneas do tipo granito (Monzogranito, Granitoide, Sienogranito), tendo como características uma dureza maior e sendo mais resistente aos efeitos do intemperismo. A região pertencente à Planície Costeira apresentou índice de fragilidade Muito Alto, abrangendo 33,4\% da área do município, esta é uma área que experimenta constantemente a influência da água, ficando mais suscetível ao intemperismo. É formada por rochas sedimentares pertencentes à família dos arenitos, cascalhos e argilas. Além das causas naturais do intemperismo neste tipo de ambiente, a ação antrópica e o modo como o solo é utilizado vêm influenciado e acelerado esse processo.

O solo conferiu índices de fragilidade: Muito Alto que abrangeu 2,7\% da área do município localizadas nas porções extremas oeste e leste; e Alto que incluiu 97,3\% da área localizada na parte central. Na região do Escudo Cristalino Sul-Riograndense os solos possuem sérios problemas, como horizontes muito rasos, geralmente ácidos, apresentando dificuldades na retenção de água, além de suscetibilidade à erosão devido ao relevo íngreme (LIMA, 2006), estas áreas incluem os tipos Argissolo Vermelho Amarelo $\left(1118,27 \mathrm{~km}^{2}\right)$ e o Neossolo Litólico $\left(16,02 \mathrm{~km}^{2}\right)$. Já os solos da Planície Costeira são pobres, parcialmente salinos, pouco consolidados e permeáveis, inclui o Planossolo Hidromórfico $\left(874,69 \mathrm{~km}^{2}\right)$. O estudo de 


\section{GESTÃO \& SUSTENTABILIDADE} AMBIENTAL

\section{DUnisul}

Anjinho et al. (2021), corroboram com esses resultados, ressaltando que solos compostos com alto teor de areia ou conteúdo de silte são mais frágeis do que aqueles com maior teor de argila.

O critério ocupação humana proporcionou índices de fragilidade Muito Baixo que compreendeu a maior parte da área do município (99,5\%); Alto que abrangeu a área rural $(0,03 \%)$ e Muito Alto que compreendeu a área urbana $(0,4 \%)$. As áreas de ocupação humana têm como característica principal a presença de aglomerados urbanos sem esgotamento sanitário. O esgotamento sanitário deve ser feito por fossa séptica e/ou filtro biológico ou sumidouro, a fossa séptica padrão, no entanto, dos 7.930 imóveis na área urbana, 16,4\% utilizam a fossa séptica padrão, já na área rural das 1.690 famílias entrevistadas 57\% utilizam este tipo de alternativa, de acordo com o Plano Municipal de Saneamento Básico Participativo de São Lourenço do Sul (PREFEITURA MUNICIPAL DE SÃO LOURENÇO DO SUL, 2014). A inexistência ou a baixa adesão ao sistema de esgotamento adequado na área urbana do município associado à concentração da população favorece a poluição das águas do Arroio São Lourenço, elevando a fragilidade do ambiente.

O critério mata ciliar proporcionou índices de fragilidade Alto que compreendeu 7,2\% da extensão do município, representados pelas áreas de $30 \mathrm{~m}$ no entorno de toda a malha hidrográfica; Médio (77,6\%) para os espaços a $500 \mathrm{~m}$ das áreas de $30 \mathrm{~m}$ e índice Baixo que incluiu $15,2 \%$ da área do município. São Lourenço do Sul possui uma extensa malha hidrográfica constituída por lagunas, arroios, rios, açudes e banhados presentes em toda extensão do território, principalmente na região de planície (SAUSEN et al., 2012). As áreas de mata ciliar são áreas que apresentam uma grande importância ambiental e são protegidas por lei.

A área urbana do município está localizada na bacia hidrográfica do Arroio São Lourenço. No seu curso superior e médio, nas áreas de Planalto, apresenta declividade e densidade de drenagem variando de alta a média, o que facilita o escoamento superficial, a erosão e o transporte de materiais. Na área de Planície, o curso inferior apresenta o padrão de drenagem meândrico, com curvas sinuosas, em alguns trechos formando semicírculos, o que favorece o acúmulo de águas, e em momentos de grande vazão podem se tornar pontos críticos e facilitar o extravasamento desta para a planície de inundação (SAUSEN et al., 2012; STEINMETZ et al., 2015). Verificou-se que $84,8 \%$ da área total do município estão localizados em área com índice de fragilidade ambiental classificado como Alto e Médio, assim a 
conservação, recuperação e preservação das Áreas de Preservação Permanente (APP) ao longo da malha hidrográfica, o monitoramento, fiscalização e a elaboração de campanhas de conscientização para evitar possíveis ocupações irregulares se tornam primordiais.

O critério cobertura vegetal e uso do solo proporcionou índices de fragilidade: Muito Alto $(1,3 \%)$ que incluíram as áreas de captação e uso diversificado da água, solo impermeabilizado e as áreas arenosas; Alto (39,5\%) áreas de vegetação florestal, de pastagens e as lavouras temporárias (cebola, arroz); Médio $(59,1 \%)$ que incluíram as áreas de vegetação florestal, de pastagens, pecuária bovina, reflorestamento e lavoura diversificada (soja, milho) e de índice Baixo (0,09\%) compreenderam as áreas de vegetação campestre. As áreas de vegetação natural determinam uma menor fragilidade, principalmente devido à interceptação de chuva e capacidade de retenção de água (NGUYEN et al., 2016). Os resultados expõem a necessidade de se considerar a aplicação de estratégias de manejo adequadas para esses usos do solo, sendo prioritária a intervenção voltada para a conservação dos recursos naturais da bacia.

O índice de fragilidade para o critério declividade foi: Muito Alto em áreas com declividade superior a 30\% (0,09\%) representando um relevo muito abrupto; Alto $(0,8 \%)$ relevo abrupto; Médio $(5,4 \%)$ relevo ondulado; Baixo $(19,0 \%)$ relevo suavemente ondulado e o índice Muito Baixo (74,7\%) apresentando um relevo plano. De acordo com Sausen et al. (2012), nas declividades de 0 a $5 \%$ o escoamento superficial é lento ou médio e a erosão hídrica não oferece maiores problemas. São áreas favoráveis à ocupação e usos diversos, com exceção daquelas definidas como áreas de preservação e com risco de inundação. A área urbana de São Lourenço do Sul em sua maior parte está localizada em declividades que variam de $0 \%$ a $3 \%$ e muito próximo ou em áreas sujeito a inundação, provocadas pelo Arroio São Lourenço ou pela Laguna dos Patos.

De posse da análise e dos mapas temáticos de índice de fragilidade de cada critério estudado, aplicou-se o modelo IFA e o resultado pode ser visualizado na Figura 2.

Verificou-se que as áreas ocupadas pelos índices de fragilidade Muito Alto, Alto e Médio, foram 30,3\%,67,1\% e 2,6\%, respectivamente. Observou-se que o índice de fragilidade Muito Alto está diretamente associado às áreas de planícies fluviais e às áreas de maior declividade, representando um relevo muito abrupto concentradas na região de planalto. As áreas de planícies fluviais estão incluídas no índice de fragilidade Muito Alto, pois podem ser acometidas por inundações que podem ocasionar erosão fluvial e, por conseguinte, possíveis 


\section{¿Unisul}

assoreamentos mais a jusante. Já o índice de fragilidade Alto se espalha por toda extensão do município. Este está associado principalmente à cobertura vegetal e uso do solo e a extensa malha hidrográfica que o município apresenta. $\mathrm{O}$ índice de fragilidade Médio ocupa pequenas áreas e se limita a região de planalto.

Figura 2 - Mapa temático do índice de fragilidade ambiental do município de São Lourenço do Sul, utilizando o modelo IFA."

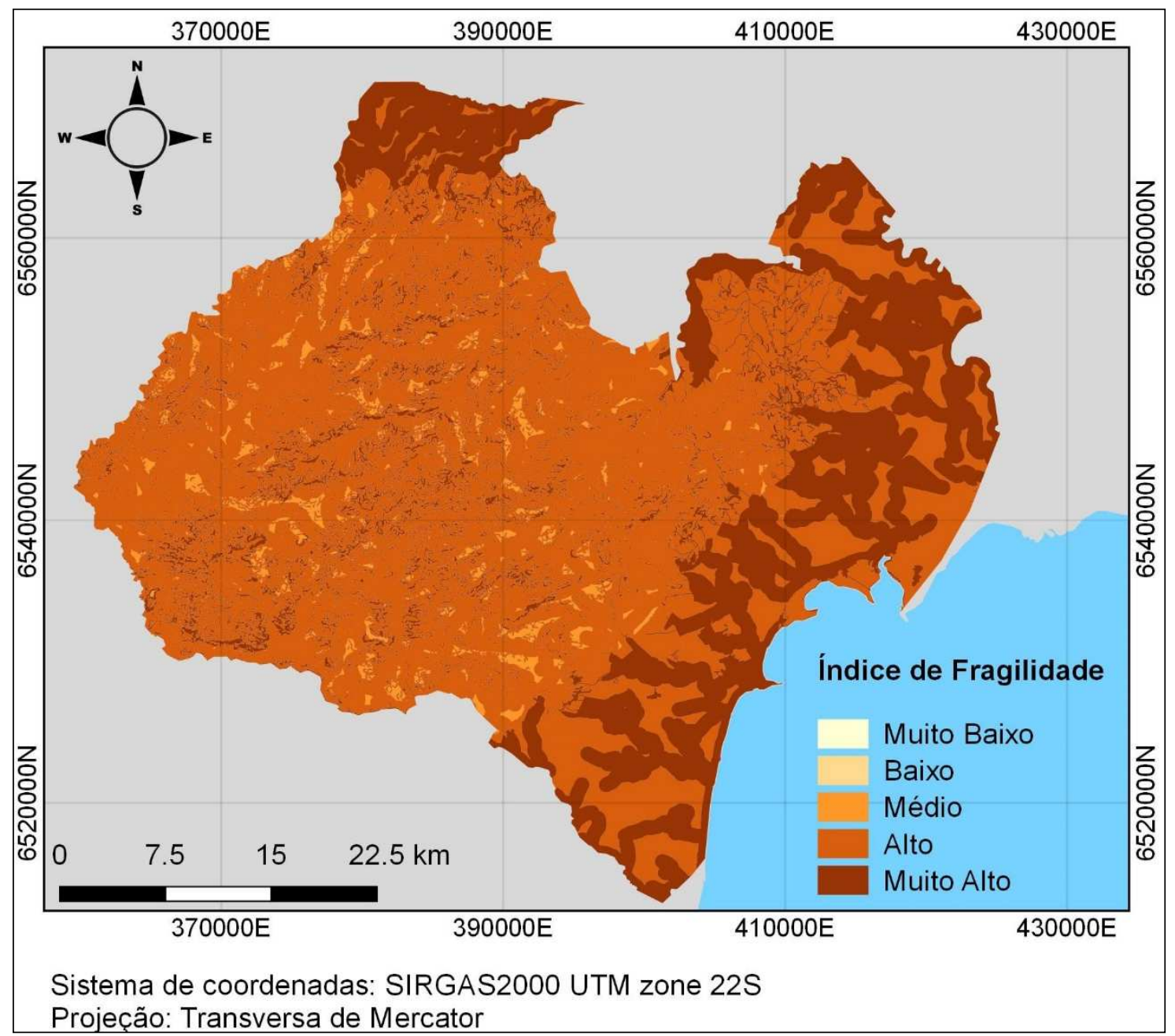

Fonte: Elaborado pelos autores.

O município de São Lourenço do Sul apresenta uma extensa malha hidrográfica, conforme demonstrado na Figura 1, esta por sua vez necessita de uma mata ciliar de qualidade. Uma vez que, para que esta cumpra o seu papel de agente filtrante, é importante observar a

Revista Gestão e Sustentabilidade Ambiental., v. 10, n. 4, p. 74-95, dez. 2021. 
largura da mata ciliar estabelecida pela legislação, o estado de desenvolvimento e conservação desta mata, as condições de manejo das áreas agrícolas no entorno, o relevo, o solo e as características de precipitação (BRANCALION et al., 2015). Assim, os gestores das bacias hidrográficas podem auxiliar promovendo programas de restauração de matas ciliares, que devem estar inseridos em planos de manejo e conservação da bacia hidrográfica. Pois, o planejamento do uso da terra, de acordo com Anjinho, et al. (2021) e Schwilch et al. (2018) deve levar em consideração as características naturais da bacia no que diz respeito à produção e transporte de sedimentos, e pode favorecer o desenvolvimento socioeconômico e a preservação do meio ambiente.

Em função da recorrência de inundações no município de São Lourenço do Sul existe um interesse e a preocupação dos gestores e planejadores em solucionar e buscar alternativas para o problema de inundações. No entanto, o município precisa olhar com urgência para um dos pontos-chave que originam estes desastres, as matas ciliares, presentes principalmente na área rural. Ainda não é conhecido o quanto estão degradadas as margens da malha hidrográfica do município, assim o Cadastro Ambiental Rural (CAR) pode ser utilizado como ferramenta para que se possa conhecer o nível de conservação das matas ciliares. De qualquer forma, é preciso começar a semear a ideia, principalmente entre os produtores rurais, da importância da recomposição das matas ciliares e da proteção das nascentes, a fim de que o município possa desfrutar de uma água para consumo de qualidade e da proteção nos diversos níveis que as matas ciliares proporcionam. De acordo com a Estratégia Internacional para Redução de Desastres (ISDR, 2002): as inundações dos rios e lagos são agravadas pelo desmatamento, pois o desmatamento e o mau uso do solo potencializam processos erosivos e assoreiam os rios, e rios assoreados tendem a causar inundação. Nesse sentido Leandro et al. (2021) ressaltam que a delimitação das áreas com maior fragilidade ambiental é essencial para que os órgãos públicos responsáveis consigam planejar, de forma controlada e sem impactar negativamente o meio ambiente, o crescimento das áreas urbanas e, consequentemente, devolver segurança à população por meio de dispositivos de monitoramento das regiões, elevando a qualidade de vida local.

\section{Conclusões}

Revista Gestão e Sustentabilidade Ambiental., v. 10, n. 4, p. 74-95, dez. 2021. 


\section{GESTÃO \& SUSTENTABILIDADE} AMBIENTAL

\section{৩unisul}

O modelo IFA se mostrou eficaz e identificou, na área de estudo, que os índices de fragilidade Muito Alto, Alto e Médio, representam 30,3\%, 67,1\% e 2,6\%, respectivamente, da área total do município. $\mathrm{O}$ índice de fragilidade Muito Alto está associado às áreas de planícies fluviais. Por outro lado o índice de fragilidade Alto está relacionado principalmente à cobertura vegetal, o uso do solo e a extensa malha hidrográfica do município.

Os mapeamentos realizados utilizaram dados multiescalares gerando um resultado final que atende uma escala de 1:50.000. Para uma delimitação mais detalhada das áreas problemáticas existe a necessidade de dados com resolução espacial maior. Outro ponto importante é que os gestores, planejadores e os usuários do espaço-territorial estejam cientes de que o uso inadequado dos recursos naturais, a ocupação de áreas com maior sensibilidade natural e o desmatamento são os principais fatores que potencializam a ocorrência de desastres naturais. Salienta-se que a frequência de ocorrência destes eventos vem se intensificando ao longo dos anos, à medida que os fatores desencadeadores são amplificados e ultrapassada a capacidade de resiliência dos elementos naturais.

\section{Referências}

AKBARI, M., NEAMATOLLAHI, E., NEAMATOLLAHI, P. Evaluating land suitability for spatial planning in arid regions of eastern Iran using fuzzy logic and multi-criteria analysis. Ecological Indicators, n. 98, p. 587-598, 2019.

ANJINHO, P. S. et al. Environmental fragility analysis in reservoir drainage basin land use planning: A Brazilian basin case study. Land Use Policy, v. 100, p. 104946, 2021.

APS, R. et al. Marine environmental vulnerability and cumulative risk profiles to support ecosystem-based adaptive maritime spatial planning. ICES Journal of Marine Science, v. 75, n. 7, p. 2488-2500, 2018.

ARRIAGADA, L. et al. A new method to evaluate the vulnerability of watersheds facing several stressors: A case study in mediterranean Chile. Science of The Total Environment, v. 651, p. 1517-1533, 2019.

BARBOSA JUNIOR, L. C. O impacto dos desastres naturais sobre crescimento econômico: o caso de São Lourenço do Sul - RS (2011). Trabalho de Conclusão de Curso. Rio Grande: FURG, 2017.

BRANCALION, P. H. S.; GANDOLFI, S.; RODRIGUES, R. R. Restauração florestal. São Paulo: Oficina de Textos, 2015.

CAMPOS, J. A. et al. Environmental fragility and land use capacity as instruments of environmental planning, Caratinga River basin, Brazil. Environmental Earth Sciences, v. 80 , n. 7, p. $1-13,2021$.

Revista Gestão e Sustentabilidade Ambiental., v. 10, n. 4, p. 74-95, dez. 2021. 
CECCONELLO, S. T. Análise e mapeamento da fragilidade ambiental do município de Pelotas/RS. Dissertação Mestrado. Pelotas: UFPEL, 2019.

CEPED/RS. CENTRO UNIVERSITÁRIO DE ESTUDOS E PESQUISAS SOBRE DESASTRES. Mapeamento de vulnerabilidade de áreas suscetíveis a deslizamentos e inundações - São Lourenço do Sul/RS. Relatório. Porto Alegre, 2015. Disponível em: $<\mathrm{ftp}$ //ftpcenad.mi.gov.br/mapeamentos/RS>

CORTE, A. P. D. et al. Environmental fragility of Iguaçu river watershed, Paraná, Brazil. Bosque (valdivia), v. 36, n. 2, p. 287-297, 2015.

CREPANI, E. et al. Sensoriamento Remoto e Geoprocessamento Aplicado ao

Zoneamento Ecológico Econômico e ao Ordenamento Territorial. São José dos Campos: INPE, 2001.

CRUZ, B. B. et al. Environmental fragility framework for water supply systems: a case study in the Paulista Macro Metropolis area (SE Brazil). Environmental Earth Sciences, v. 76, n. 441, p. 1-13, 2017.

CUNHA, N. G; SILVEIRA, R. J. C; SEVERO, C. R. S. Estudo de solos do município de São Lourenço do Sul - RS. Pelotas: Embrapa Clima Temperado, 2006.

FELGUEIRAS, C. A. Modelagem ambiental com tratamento de incertezas em sistemas de informação geográfica: o paradigma geostatístico por indicação. Tese Doutorado. São José dos Campos: INPE, 2001.

FEPAM. Fundação Estadual de Proteção Ambiental Henrique Luiz Roessler - RS. Biblioteca Digital. Disponível em: $<$ http://www.fepam.rs.gov.br/biblioteca/geo/bases_geo.asp $>$ Acesso em: abr. 2020.

IBGE. INSTITUTO BRASILEIRO DE GEOGRAFIA E ESTATÍSTICA. Catálogos de Metadados, 2002 e 2004. Disponível em:

$<$ http://www.metadados.geo.ibge.gov.br/geonetwork_ibge/srv/por/main.home $>$. Acesso em: abr. 2020.

Banco de Dados Cidades@. Disponível em:

$<$ https://cidades.ibge.gov.br/brasil/rs/sao-lourenco-do-sul/panorama >. Acesso em: jun. 2021.

Censo demográfico 2010. Famílias e domicílios. 2010. Disponível em:

<www.ibge.gov.br>. Acesso em: abr. 2018.

ISDR. INTERNATIONAL STRATEGY FOR DISASTER REDUCTION. Living with risk: a global review of disaster reduction initiatives. Preliminary version. Geneva, Switzerland: UN/ISDR, 2002.

LEANDRO, D. et al. Preposição de metodologias para validação de modelagens dos índices de fragilidade ambiental. In: Geotecnologias aplicadas às Ciências Ambientais. Pelotas: LGEA, 2021.

LEANDRO. D. Modelagem de fragilidade ambiental usando índices baseados em dados especiais e com suporte de sistema especialista. Tese Doutorado. Curitiba: UFPR, 2013.

LIMA, M. I. F. Paisagem, terroir e sistemas agrários: um estudo em São Lourenço do Sul. Dissertação Mestrado. Porto Alegre: UFRGS, 2006. 


\section{GESTÃO \& SUSTENTABILIDADE} AMBIENTAL

\section{¿Unisul sim}

MACEDO, D. R. et al. Development and validation of an environmental fragility index (EFI) for the neotropical savannah biome. Science Of The Total Environment, v. 635, p. 12671279, 2018.

MANFRÉ, L. A. et al. Environmental fragility evaluation and guidelines for environmental zoning: a study case on Ibiuna (the Southeastern Brazilian region). Environmental Earth Sciences, v. 69, n. 3, p. 947-957, 2013.

NGUYEN, A. K. et al. Zoning eco-environmental vulnerability for environmental management and protection. Ecological Indicators, v. 69, p. 100-117, 2016.

NGUYEN, K. A.; LIOU, Y. A. Global mapping of eco-environmental vulnerability from human and nature disturbances. Science of The Total Environment, v. 664, p. 995-1004, 2019.

OLIVEIRA-ANDREOLI, E. Z. et al. Multi-temporal analysis of land use land cover interference in environmental fragility in a Mesozoic basin, southeastern Brazil.

Groundwater for Sustainable Development, v. 12, p. 100536, 2021.

PREFEITURA MUNICIPAL DE SÃO LOURENÇO DO SUL. Plano Municipal de Saneamento Básico Participativo de São Lourenço do Sul. 2014. Disponível em: $<$ https://portal.tce.rs.gov.br/pmsr/PMSB/S\%C3\%A3o\%20Louren\%C3\%A7o\%20do\%20Sul/P MSB_Sao_Lourenco_do_Sul.pdf $>$ Acesso em: jun. 2018.

ROSS, J. L. S. Análise Empírica da Fragilidade dos Ambientes Naturais e Antropizados. Revista do Departamento de Geografia, São Paulo, n. 8, p. 63-74, 1994.

SAHOO, S. et al. Future Scenarios of Environmental Vulnerability Mapping Using Grey Analytic Hierarchy Process. Natural Resources Research, v. 28, p. 1461-1483, 2019.

SAHOO, S.; DHAR, A.; KAR, A. Environmental vulnerability assessment using Grey Analytic Hierarchy Process based model. Environmental Impact Assessment Review, v. 56, p. 145-154, 2016.

SANTOS, R. M. et al. Análise da fragilidade ambiental no município de Tamboara - PR: aplicação e estudo comparativo de duas metodologias. Geoambiente, n. 3, p. 93-120, 2010.

SAUSEN, T. M. et al. Análise do evento de inundação brusca ocorrido em São Lourenço do Sul, RS, em 10 de março de 2011. São José dos Campos: INPE, 2012. 207 p.

SCHWILCH, G. et al. Assessing impacts of soil management measures on ecosystem services. Sustainability (Switzerland), v. 10, n. 12, 2018.

SPÖRL, C. Metodologia para elaboração de modelos de fragilidade ambiental utilizando redes neurais. Tese Doutorado. São Paulo: USP, 2007.

SPÖRL, C.; ROSS, J. L. S. Análise comparativa da fragilidade ambiental com aplicação de três modelos. Revista GeoUSP - Espaço e Tempo, São Paulo, n. 15, p. 39-49, 2004.

STEINMETZ, A. A. et al. Influência das características morfométricas nas enchentes urbanas: estudo de caso da bacia hidrográfica do Arroio São Lourenço/RS. In: XXI Simpósio

Brasileiro de Recursos Hídricos. Anais [...] Brasília, 2015.

Revista Gestão e Sustentabilidade Ambiental., v. 10, n. 4, p. 74-95, dez. 2021. 
STEYAERT, L. A perspective on the state of environmental simulation modeling. In: Goodchild, M. F.; Bradley, O. P.; Steyaert L. T. ed. Environmental Modeling with GIS. New York: Oxford University Press, 1993. p. 16-30.

TOMAZELLI, L.J. et al. Sistemas Deposicionais e Evolução Geológica da Planície Costeira do Rio Grande do Sul: uma Síntese. In: IANNUZZI, R.; FRANTZ, J. C. (Ed.). 50 anos de geologia: Instituto de Geociências, contribuições. Porto Alegre: Comunicação e Identidade, 2007.

TOMINAGA, L. K.; SANTORO, J.; AMARAL, R. Desastres naturais: conhecer para prevenir. São Paulo: Instituto Geológico, 2009.

TREVISAN, D. P. et al. Environmental vulnerability index: An evaluation of the water and the vegetation quality in a Brazilian Savanna and Seasonal Forest biome. Ecological Indicators, v. 112, p. 106163, 2020.

TRICART, J. Ecodinâmica. Rio de Janeiro: IBGE/SUPREN, 1977.

ZHAO, J. et al. Environmental vulnerability assessment for mainland China based on entropy method. Ecological Indicators, v. 91, p. 410-422, 2018. 